\title{
Turbidity and TSS removal from textile wastewater using a combination of natural and chemical coagulants
}

\author{
Noor Shakir Ali ${ }^{1}$, Ali Jwied Jaeel ${ }^{2}$ \\ ${ }^{1,2}$ Civil Engineering Department, Wasit University, Iraq. \\ **Corresponding author alijwied@gmail.com \\ Submitted: $17 / 5 / 2018$ \\ Accepted: 18/7/2018
}

\begin{abstract}
Recently natural coagulants are a consistently expanded; plants extracted coagulant which may be adopted in the coagulation-flocculation activity of textile wastewater treatment for reduction concentration of turbidity and total suspended solids. In this study, the possibility of a combination between chemical coagulant (alum) and natural plant coagulant (Capparis Spinosa) in excluding turbidity and total suspended solids from textile wastewater has been studied. A set of experiments were implemented for verifying the turbidity and TSS removal efficiency using alum and powder extracted from Capparis Spinosa plant separately. A combined dosage consisted of chemical coagulant (alum) dosages $(10,20,30$ and $40 \mathrm{mg} / \mathrm{l})$ with natural coagulant dosages $(10,20,30$ and $40 \mathrm{mg} / \mathrm{l})$ in order to detect the optimum combined percentage of both coagulants (alum and Capparis Spinosa) that produces higher removal efficiencies for both turbidity and TSS. The study found the activity of removal for both turbidity and total suspended solids increased in high performance when mixing is occurred between natural coagulant (Capparis Spinosa) and chemical coagulant (Alum). The results illustrate that the combination of $20 \mathrm{mg} / \mathrm{l}$ alum with $30 \mathrm{mg} / \mathrm{l}$ Capparis Spinosa made $99 \%$ turbidity removal and the combination of $30 \mathrm{mg} / \mathrm{l}$ alum with $30 \mathrm{mg} / \mathrm{l}$ Capparis Spinosa made $98 \%$ TSS removal.
\end{abstract}

Key word: Coagulation, textile wastewater, natural coagulant, turbidity, TSS.

1- INTRODUCTION

Quick population and industrial development in the nations of the world are deterioration the environment through the unrestrained growth of industrialization, and in addition adding to the destruction of common living spaces. The developing population and the retrogradation the environment represent the test of support improvement without ecological harm. These days, chemical compounds (from industrial) are found progressively, and a significant number of these materials have determined them into nature with unfavorable effects, which can slowly demolish the environment [1]. Numerous industries used water and discharge wastewater which contains suspended, colloidal and broke up (mineral and natural) solids, might be either too much acidic or basic and may include a high or low concentration of colored matter. These wastes normally contain natural or dangerous materials and once in a while, pathogenic bacteria. As a consequence of vast amounts of water be utilized by industries, treatment and reuse of wastewaters, at any rate, to a level safe for transfer have moved toward becoming outright need keeping in mind the end goal to evade contamination of water bodies. A large range of wastewater treatment systems having some associated marks of attention. Most usually, wastewater treatments include biological treatment, for example, nitrification, denitrification and phosphorus removal, physio-chemical treatment, for example, adsorption, reverse osmosis, precipitation, ion exchange, coagulation, and electrocoagulation. Coagulation-flocculation is a commonly used Physico-chemical approach in the treatment of industrial wastewater because it discharges colloidal particles and other matters. This action weakens the colloidal suspension of the particles with coagulants and eventually forces the particles to gather up with flocculants. Coagulants used as a part of wastewater treatment can be inorganic (for example, aluminum sulphate and polyaluminium chloride, $\mathrm{FeCl3}$ ), synthetic organic polymers (for instance polyacrylamide subsidiaries and polyethyleneimine) or normally happening coagulants, (for example, chitosan and microbial coagulants and plants) [2]. Some researchers have presented that the adoption of natural coagulants is a promising application in industrial wastewater treatment. For example, coagulation applied natural polymer (Chitosan) to estimate the chemical oxygen demand (COD) and color. The influence of several plant coagulants, T.foenum-graecum, Moringa oleifera, Cicer arietinum, Dolichos lablab, COD removal and turbidity from industrial milk water was investigated. In the optimal dose and $\mathrm{pH}$, the turbidity obtained performances of removal of M.oleifera, Dolichos Lablab, T.foenum-graecum and Arietinum Cicer to be $60 \%, 70 \%, 58 \%$ and $78 \%$, respectively [3]. The primary function of the coagulation process in wastewater treatment is to discard suspension colloids and turbidity. Coagulant is a chemical or natural (animal or plant origin) material inserted to the water to eliminate the causes that balance the colloids and deriving them to string up in the water. Once the coagulant is inserted in the water, the suspended solids start to agglomerate, enlarge greater with the intent that these suspended solids could be disposed down and segregated from the water suspension [4]. Recently, the adopting of several varieties of chemical and natural coagulants for the textile wastewater treatment has been studied by [5]. They discussed the removal of 
dyes from textile wastewater using chemical, and natural coagulation process and they initiated that more analysis and a great extent of practice was yet essential prior to create any complete outcomes concerning the capacity of those coagulants for the color removal from textile wastewater [6]. Natural coagulants used in some studies such as Dolichas lablab, Azadirachta Indica, Moringa Oleifera, which are locally accessible from plants [7]. In this study, a combination of two coagulants (chemical and natural) was used to investigate the optimum combined dosage for the maximum turbidity and total suspended solids removal percentages as a pretreatment for textile wastewater. The chemical coagulant was an alum, and the natural plant that used was Capparis Spinosa. Capparis Spinosa is a familiar plant of the group Capparis (Cappardaceae category). This family consists of 250 kinds of flowering plants that spread along tropics to subtropical regions. Capparis Spinosa is a permanent shrub, 0.3-1 height. It also has mostly rooted, which can continue to 6-10 meters. Capparis Spinosa is usually grown within tropical and subtropical zones, broadly developed in bare, very much washed-out soil and sunny weather. Nonetheless, it can be grown in poor soils and also rough ranges and mountains. It has additionally been accounted these kinds able to be broadly developed in various assortments of land [8] Capparis Spinosa is highly spread in several areas of the Earth from Morocco to the Crimea, Armenia, Iran, Iraq, and Turkey. Capparis Spinosa develops extensively in raining environments beginning from April to May and usually disappears within the cold periods, from October on ahead. [9]

\section{2- MATERIALS AND METHODS}

\section{2-1 Preparation of Synthetic Turbid Water}

For the preparation of synthetic turbid water, several masses of dyes in (mg) added into one litter of deionized water. In the jar test equipment, the dye solution was re-suspended by a rapid mix (300 RPM) for 5 min, followed by a slow mix (40 RPM) for $30 \mathrm{~min}$. After that, the mixers switch off for $10 \mathrm{~min}$ to for sedimentation. At the end sedimentation period, samples were taken to measure turbidity by the turbid meter. The mean values of four readings for each turbidity (NTU) were sketched in opposition to the concentration of dyes in (mg/l) as demonstrated figure (1). In order to get the linear model as shown in equation number (1) with correction coefficient $\left(\mathrm{R}^{2}\right)$ equal to $(0.9946)$, this model was used to prepare five different levels of synthetic turbid water ranged $(50,100$, 200, 400, and 800) NTU.

$\mathrm{Y}$ : represents the prepared textile water turbid.

$$
\mathrm{Y}=10.674 \mathrm{X}-0.0172
$$

$\mathrm{X}$ : represents the concentration of dyes.

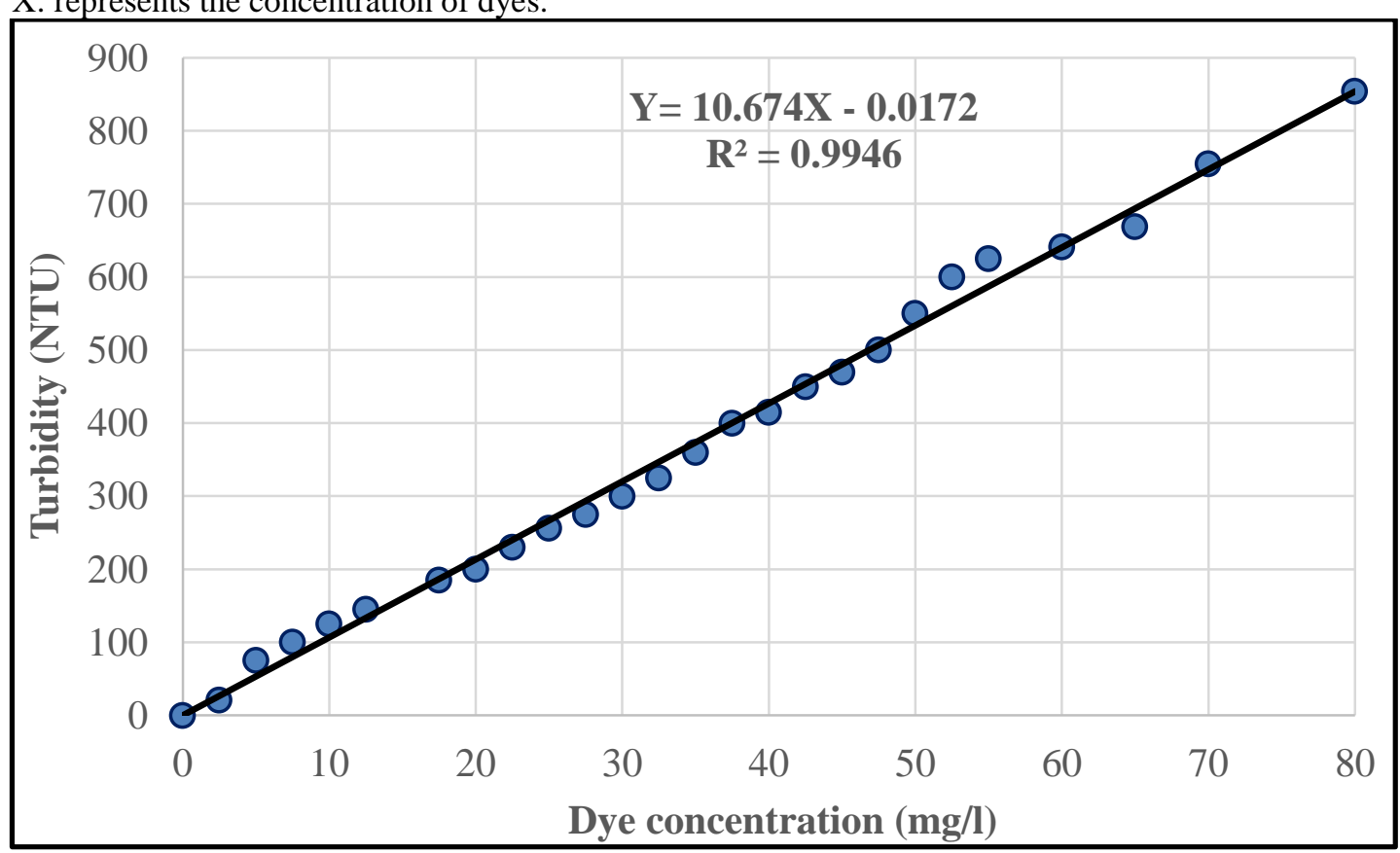

Fig. 1. Synthetic turbid textile water as a function of dye concentration

\section{2-2 Capparis Spinosa as a natural coagulant}


The Capparis Spinosa is a natural shrub (as shown in Fig. 2) living in broad range area in most of the fruits gathered, dehydrated under the effect of sun emission followed by drying using an oven for 10 hours and $60{ }^{\circ} \mathrm{C}$. After the drying finished, the Capparis Spinosa grinded and finally sieving them using 600 micrometer sieve, Capparis Spinosa powder was added to a distilled water at a mass of 1 gram in one liter of distilled water, and by volumetric analysis process, a four several dosages of coagulant were formulated as (10, 20, 30, and $40 \mathrm{mg} / \mathrm{l})$. The Capparis Spinosa solution was filtered with a filter paper before being used.

2-3 Formulation of alum solution

Regular standard solutions of alum were formulated conceding to the APHA method for coagulation action improvement, using decomposing $10 \mathrm{gm} \mathrm{Al2}(\mathrm{SO} 4) 3.16 \mathrm{H} 2 \mathrm{O}$ ) in $1000 \mathrm{ml}$ of purified water, and using volumetric analysis process a four several dosages of alum are formulated ordered 10, 20, 30, and $40 \mathrm{mg} / \mathrm{l}$, [10].
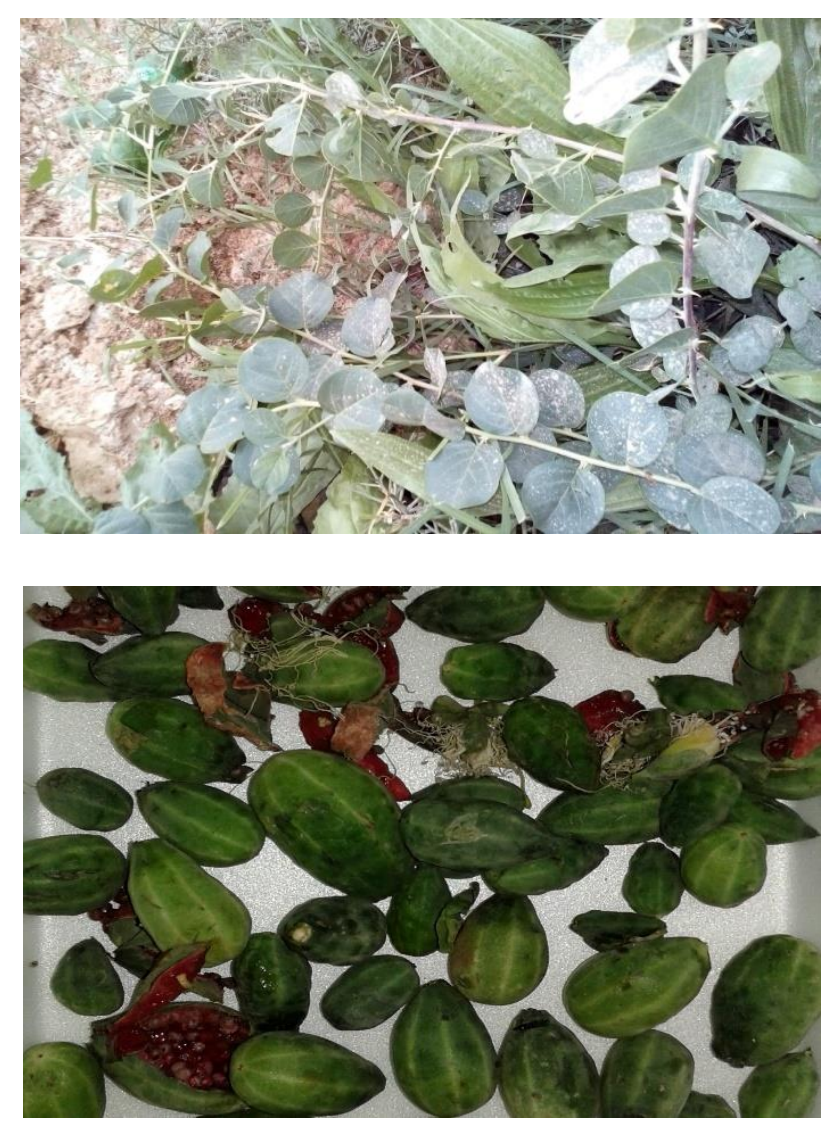

Fig. 2. Capparis Spinosa (leaves and fruits)

\section{2-4 Jar test}

A jar test is the best technique used to assess coagulation process and decide the ideal coagulation dosage. One cylinder was loaded with a litter of wastewater test. In each jar, an alternate dosage is used at various rates. In the test jar, submit a fast mix of $140 \mathrm{rpm}$ for $2 \mathrm{~min}$ to spread the coagulant in all solution (coagulation process), later slow mix $40 \mathrm{rpm}$ for 30 minutes to shape flocs (flocculation process). This is trailed by 30 -minute s settling to settle particles (settling process). Ultimately, when slow mix and settling time were finished, the samples were pulled from an elevation of 3-6 cm beneath the surface of each cylinder by a pipette. This sample was tested by the turbid meter and TSS test to decide the ideal dosage of coagulant.

\section{2-5 Mixing ratios for combined coagulants}

Firstly, each optimized coagulant dosage is discovered separately for each coagulant. Then after that, a mixed dosage involved of alum dosages $(10,20,30$ and $40 \mathrm{mg} / \mathrm{l})$ with repeated ranges of Capparis Spinosa started from 10 $\mathrm{mg} / \mathrm{l}$ to $40 \mathrm{mg} / \mathrm{l}$ in order to calculate the optimized commixing percentages of these two coagulants ( alum and 
Capparis Spinosa), the mixing ratios are shown in Table 1 where $\mathrm{R} 1$ refers to a mixing ratio of $10 \mathrm{mg} / \mathrm{l}$ of alum and $10 \mathrm{mg} / \mathrm{l}$ of Capparis Spinosa, R2 refers to a mixing ration of $20 \mathrm{mg} / \mathrm{l}$ of alum and $10 \mathrm{mg} / \mathrm{l}$ of Cappris Spinosa and so on. The influence of commixing concentration percentages of both types of coagulant on the removal of turbidity and total suspended solids is tested.

Table (1): Combination ratios for chemical and natural coagulants

\begin{tabular}{|c|c|c|c|c|c|}
\hline \multirow{6}{*}{ 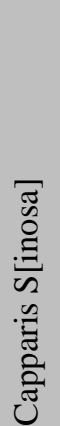 } & \multicolumn{5}{|c|}{ Alum } \\
\hline & & $10 \mathrm{mg} / \mathrm{l}$ & $20 \mathrm{mg} / 1$ & $30 \mathrm{mg} / \mathrm{l}$ & $40 \mathrm{mg} / \mathrm{l}$ \\
\hline & $10 \mathrm{mg} / \mathrm{l}$ & R1 & R2 & R3 & R4 \\
\hline & $20 \mathrm{mg} / \mathrm{l}$ & R5 & R6 & R7 & R8 \\
\hline & $30 \mathrm{mg} / 1$ & R9 & R10 & R11 & R12 \\
\hline & $40 \mathrm{mg} / \mathrm{l}$ & R13 & R14 & R15 & R16 \\
\hline
\end{tabular}

\section{3- RESULTS AND DISCUSSIONS}

\section{3-1 Effect of alum and Cappris Spinosa doses on turbidity Removal}

After using different ranges of dyes to produce different ranges of turbidities (50, 100, 200, 400, and 800 NTU), the findings demonstrated that the optimized concentrations to reduce turbidity adopting alum, and Capparis Spinosa were $30 \mathrm{mg} / \mathrm{l}$ for all the ranges of turbidities, the maximum turbidity reduction efficiencies were $92 \%, 86 \%$ subsequently for 200 NTU synthetic textile wastewater as shown in the Figs. 3 and 4, respectively.

3-2 Effect of alum and Cappris Spinosa doses on TSS removal

After using different ranges of dyes to produce different ranges of turbidities (50,100, 200, 400, and 800 NTU), the findings demonstrated that the optimized concentrations to reduce total suspended solids adopting alum, and Capparis Spinosa were also $30 \mathrm{mg} / \mathrm{l}$ for all the ranges of turbidities, the maximum turbidity reduction efficiencies were $89 \%$, and $83 \%$ subsequently for 200 NTU synthetic textile wastewater as shown in the Figs. 5 and 6 , respectively.

3-3 Effect of the combined doses (alum and Cappris Spinosa) on turbidity and TSS removal

Several sets of examinations were done using jar test apparatus for sixteen different mixing ratio from R1 to R16 as previously explained to investigate the best dosage for a combination of alum and Capparis Spinosa to remove turbidity from synthetic textile wastewater with constant turbidity (200 NTU), as shown in Fig. 7 the optimum mixing ratio was $\mathrm{R} 7$ which refers to a mixing ratio of $30 \mathrm{mg} / \mathrm{l}$ alum with $20 \mathrm{mg} / \mathrm{l}$ Capparis Spinosa with a maximum turbidity removal efficiency was $99 \%$. As shown in Fig. 8, the optimum mixing ratio was R11 which refers to a mixing ratio of $30 \mathrm{mg} / \mathrm{l}$ alum with $30 \mathrm{mg} / \mathrm{l}$ Capparis Spinosa with a maximum TSS removal efficiency was $98 \%$. This extremely reduction of turbidity may be associated to the grinded Capparis Spinosa has a high adsorption activity for the colloids addition to the extreme impact about the formulation of alum hydrolysis productions that expressed the furthermost influential principle of colloids destabilization. 


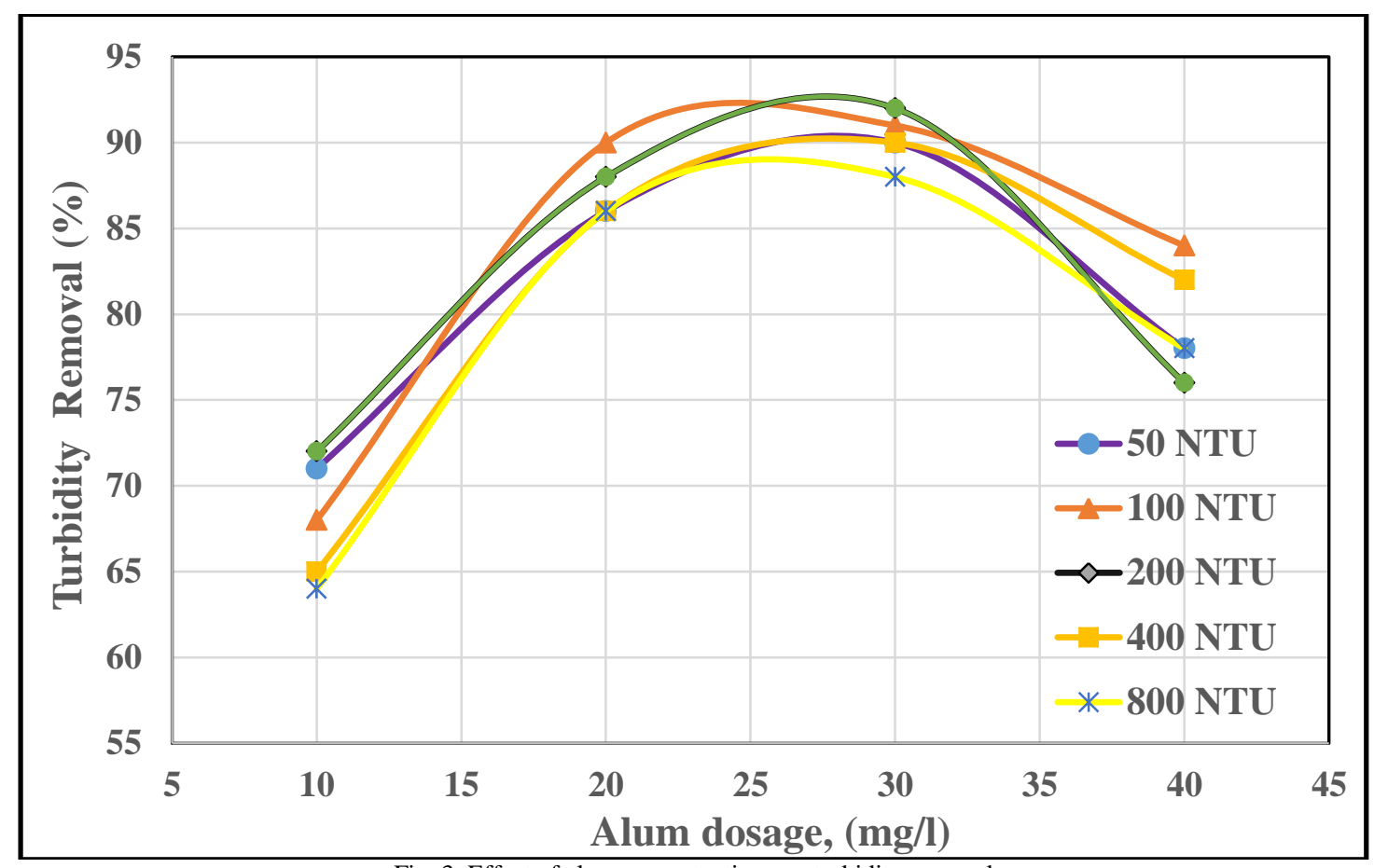

Fig. 3. Effect of alum concentrations on turbidity removal

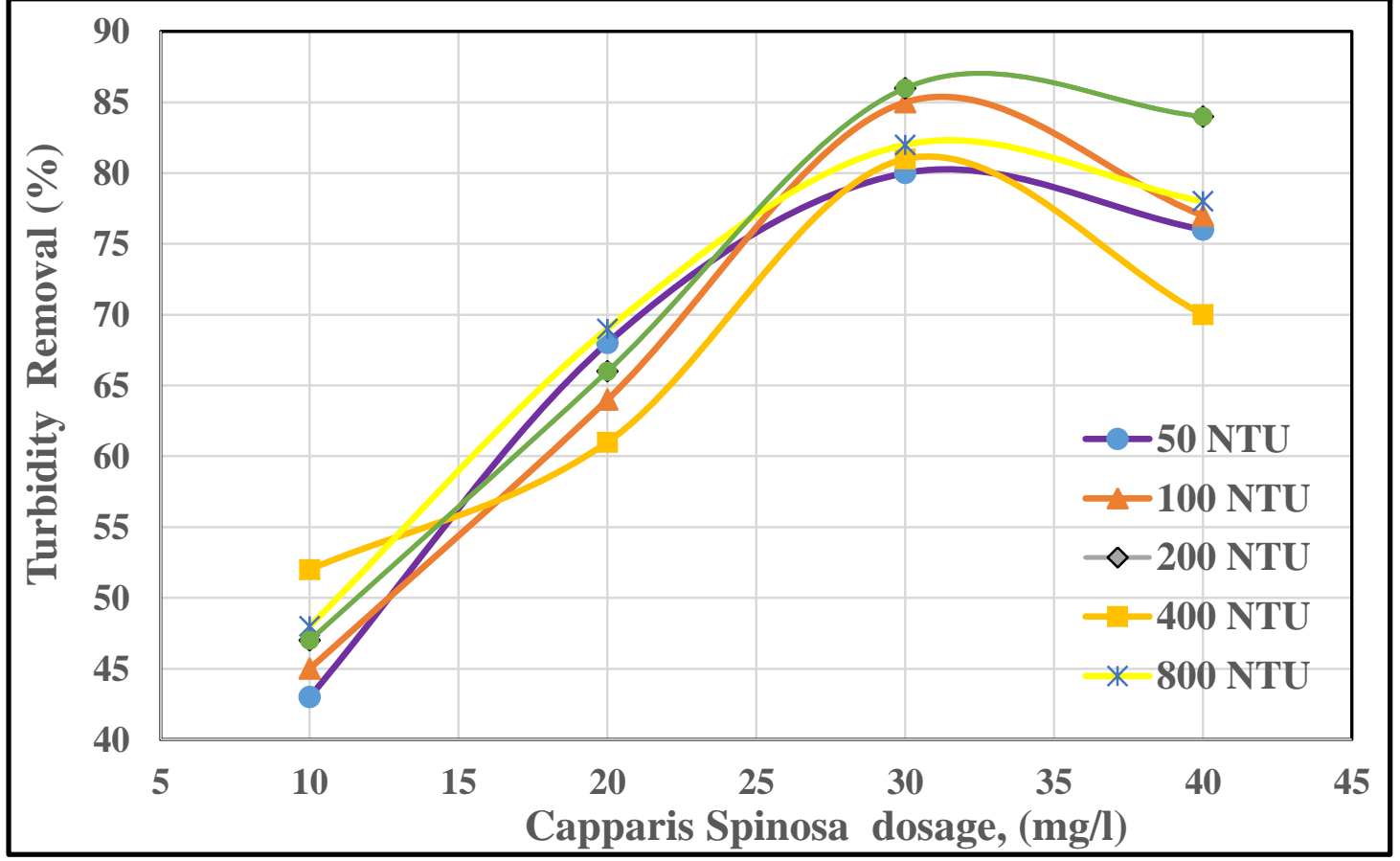

Fig. 4. Effect of Capparis Spinosa concentrations on turbidity removal 


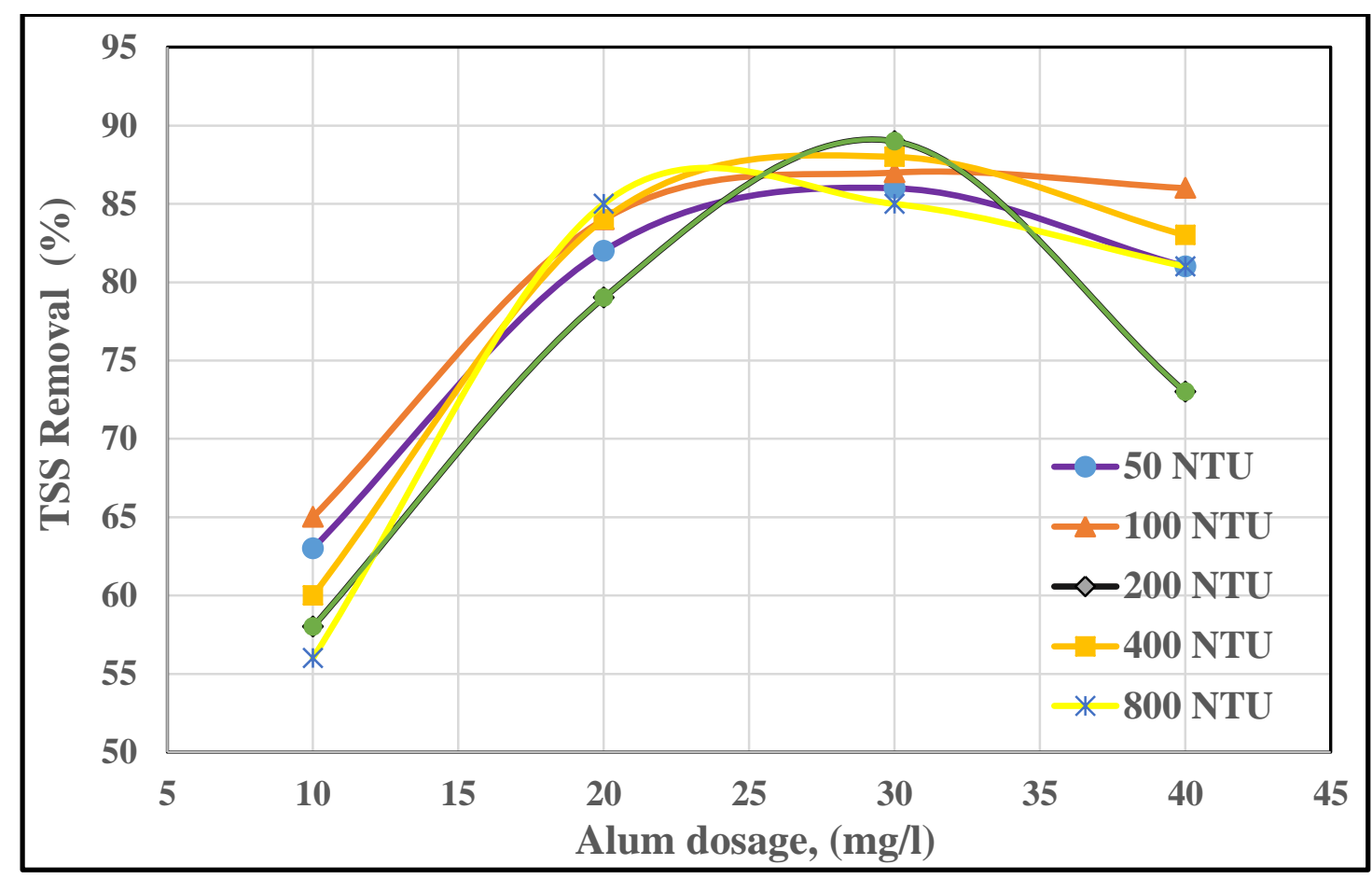

Fig. 5. Effect of alum dose on TSS removal (200 NTU)

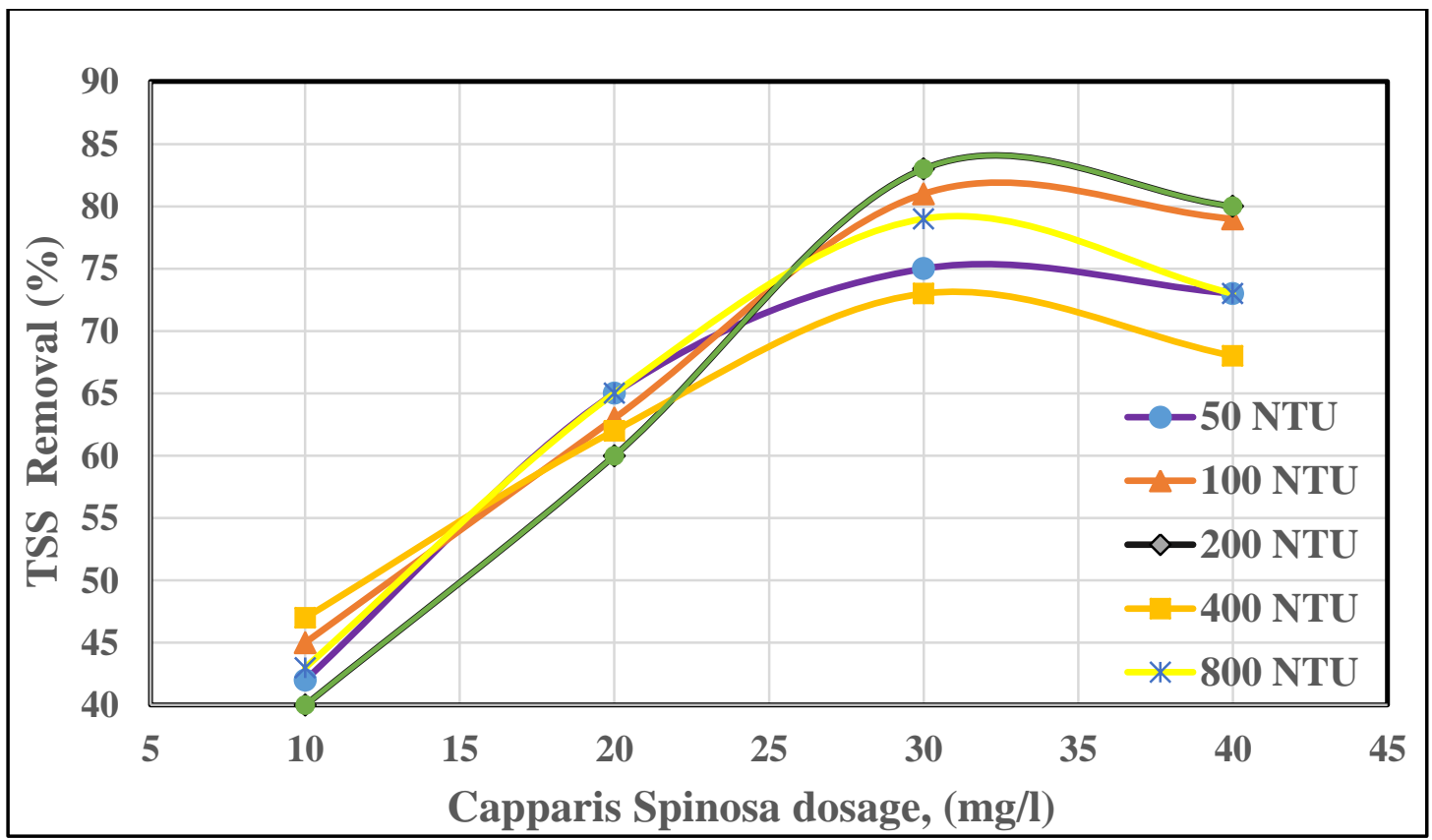

Fig. 6. Effect of Capparis Spinosa concentrations on TSS removal (200 NTU) 


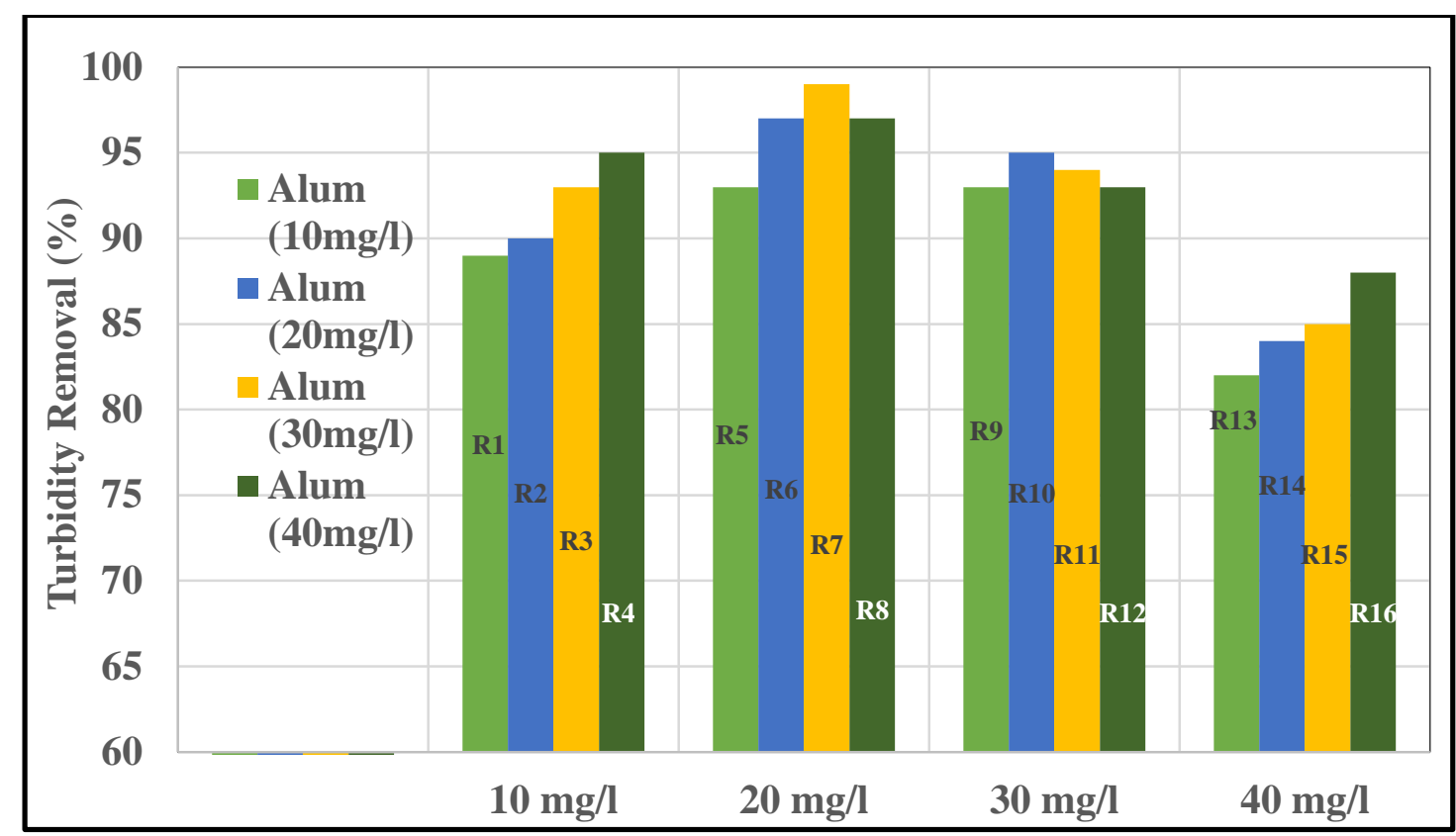

Fig. 7. Effect of the combinations of alum and Capparis Spinosa concentrations on turbidity removal

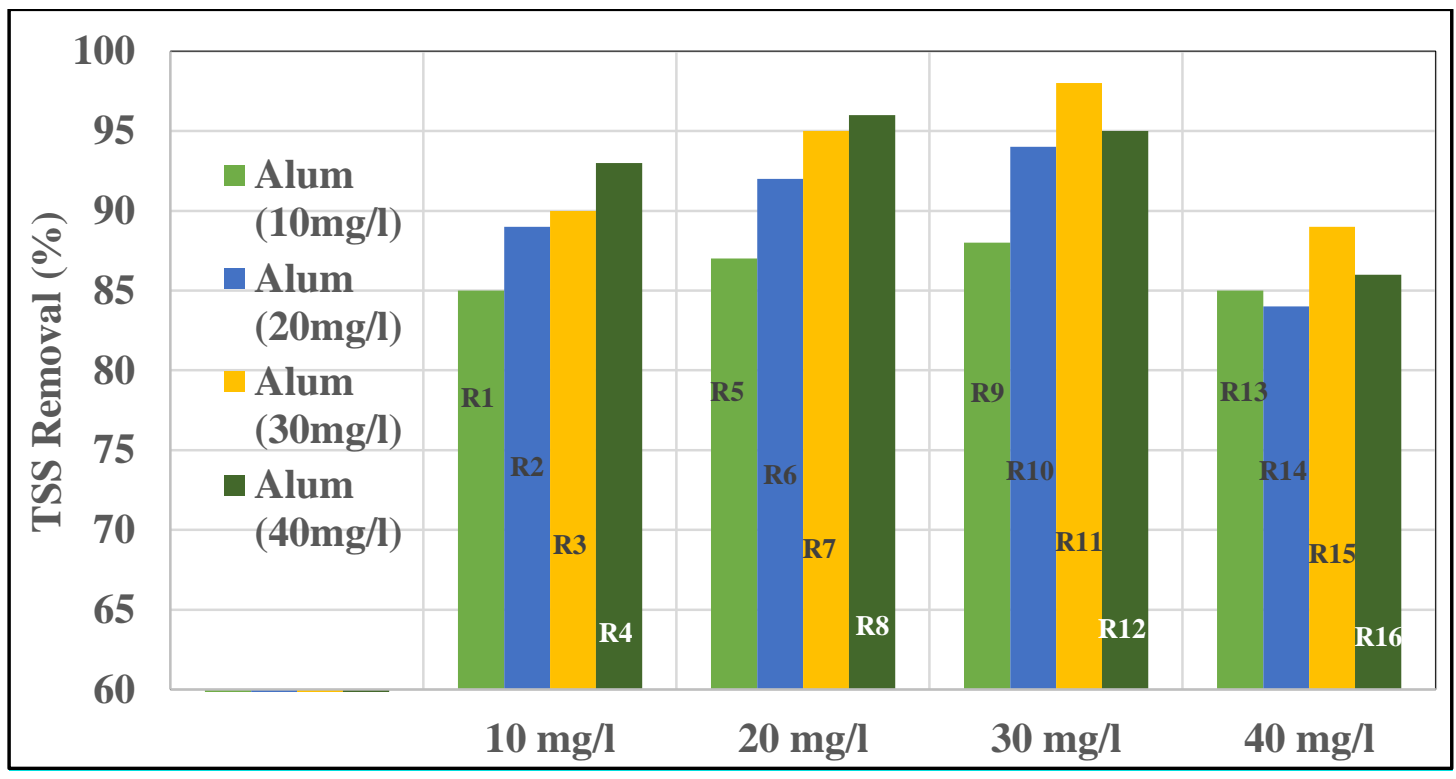

Fig. 8. Effect of the combinations of alum and Capparis Spinosa concentrations on TSS removal

\section{4- CONCLUSIONS AND RECOMMENDATIONS}

The pretreatment of dyeing materials in textile wastewater is essential and assurances protection the environment of water sources. As a result, using a common plant, Capparis Spinosa could be used as a natural coagulant in turbidity and suspended solids removal in textile wastewater pretreatment at the powerful performance. The study found the activity of removal for both turbidity and total suspended solids increased in high performance when a mixture is determined between plant coagulant (Capparis Spinosa) and chemical coagulant (alum). The research findings showed that the best-mixed percentage adopted to reduce preliminary turbidity of textile wastewater is $99 \%$ using a combination of (30 mg/l Capparis Spinosa plus $20 \mathrm{mg} / \mathrm{l}$ alum). The findings explained that the best mixed percentage adopted to reduce preliminary suspended solids of textile wastewater is $98 \%$ using a combination of (30 $\mathrm{mg} / \mathrm{l}$ Capparis Spinosa plus $20 \mathrm{mg} / \mathrm{l}$ alum).

Further studies should be done to investigate the effect of $\mathrm{pH}$, temperature and mixing velocities on the removal percentages using these combinations of natural and chemical coagulants. 


\section{5- References}

[1] M. Dehghani and M. H. Alizadeh, "The effects of the natural coagulant Moringa oleifera and alum in wastewater treatment at the Bandar Abbas Oil Refinery" Environmental Health Engineering and Management Journal, Vol.3, No. 4, pp 225-230, 2016.

[2] R. R. Ayangunna, S. O. Giwa, and A. Gia, "Coagulation-Flocculation Treatment of Industrial Wastewater Using Tamarind Seed Powder" International Journal of ChemTech Research, 9, pp 771-780, (2016).

[3] S. Choubey, S.K. Rajput and K.N. Bapat, "Comparison of some natural coagulants bioremediation". International Journal of Technology and Advanced Engineering, 2, pp 429-434, (2012).

[4] Q. Imran, M. A. Hanif, M. S. Riaz, S. Noureen, T. M. Ansari, and H. N. Bhatti "Coagulation/Flocculation of Tannery Wastewater Using Immobilized Chemical Coagulants, 10, pp 79-86, (2012).

[5] A. K. Verma, R. R. Dash, and P. Bhunia, "A review on chemical coagulation/flocculation technologies for removal of colour from textile wastewaters", Journal of Environmental Management, 93, p.p 154-68, (2012).

[6] J. Saravanan, D. Priyadharshini, A. Soundammal, G. Sudha, and K. Suriyakala, "Wastewater Treatment using Natural Coagulants" SSRG International Journal of Civil Engineering, 4, pp. 40-42, (2017).

[7] Md. Asrafuzzaman, A. N. M. Fakhruddin, and Md. Alamgir Hossain, "Reduction of Turbidity of Water Using Locally Available Natural Coagulants," ISRN Microbiology, 1, Article ID 632189, 6 pages, (2011).

[8] S. Mohammad, H. Kashani, and Z. Azarbad, "Capparis spinosa L. Propagation and medicinal uses", Life Science Journal 9, pp. 684 -686, (2012).

[9] N. Tlili, H. Mejri, F. Anouer, E. Saadaoui, A. Khaldi, N. Nasri, "Phenolic profile and antioxidant activity of Capparis spinosa seeds harvested from different wild habitats”, Ind Crops Prod, 76, pp. 930-935, (2015).

[10] APHA, AWA, WPCF, 1998, Standard Methods for the Examination of Water and Wastewater, 20th edition, American Public Health Association, Washington, DC. 